\title{
PATOLOGIAS DO SISTEMA GENITAL FEMININO DE CÃES E GATOS
}

Recebido: $24 / 07 / 2016$

Aceito: 08/02/2017

\author{
SAPIN, Carolina da Fonseca '; \\ SILVA-MARIANO, Luísa Cerqueira "; \\ FIALHO-XAVIER, Aline Galiza ${ }^{2}$; \\ TIMM, João Paulo Teló ${ }^{2}$; \\ PIOVESAN, Andressa Dutra "; \\ TILLMANN, Mariana Teixeira '; \\ GEHVER, Cristina Fernandes ${ }^{3}$; \\ GRECCO, Fabiane Borelli ${ }^{3}$.
}

${ }^{1}$ Programa de Pós-Graduação em Veterinária/UFPEL; ${ }^{2}$ Graduação em Medicina Veterinária/UFPEL; ${ }^{3}$ Professora Adjunta - Departamento de Patologia Animal/UFPEL.

\section{RESUMO}

\begin{abstract}
Onsiderando a sobrevivência de uma espécie, o sistema reprodutivo é um dos sistemas mais importantes. As gônadas indiferenciadas são formadas por células germinativas que quando estimuladas pelo fator de diferenciação testicular se diferenciam em testículos, ou quando não estimuladas, em ovários. Aqui serão abordadas lesões do desenvolvimento sexual e anomalias da formação e do desenvolvimento gonadal feminino. Dentre as patologias abordadas estão o complexo hiperplasia endometrial cística piometra, metrite, neoplasmas ovarianos e uterinos.
\end{abstract}

Palavras-chave: Sistema genital feminino. Complexo hiperplasia endometrial cística piometra. Cadela. Gata. 


\section{INTRODUÇÃO}

\section{Características do sistema genital}

As gônadas indiferenciadas são formadas por células germinativas que quando estimuladas pelo fator de diferenciação testicular dão origem aos testículos, ou quando não estimuladas, dão origem aos ovários (NASCIMENTO; SANTOS, 2003). A diferenciação do fenótipo feminino ocorre a partir do desenvolvimento dos ductos paramesonéfricos, que originam a tuba uterina, o útero e a porção superior da vagina. O tubérculo genital origina a porção distal da vagina e vulva. O ovário tem como funções o desenvolvimento e a liberação de oócitos e a síntese de hormônios como o estrógeno e a progesterona, que influenciam no comportamento animal e outros órgãos para a manutenção da gestação (FOSTER, 2013).

A tuba uterina por sua vez, realiza o transporte e o depósito de espermatozóides, além de coletar e transportar o oócito e fornecer um local para ocorrer a fertilização (NASCIMENTO; SANTOS, 2003). No útero, há um ambiente estéril e inerte para o desenvolvimento do concepto, ocorrendo a troca de nutrientes, fatores tróficos, componentes imunológicos como as imunoglobulinas e metabólitos (FOSTER, 2013; NASCIMENTO; SANTOS, 2003). A cérvix atua como barreira, evitando a entrada de micro-organismos e produtos exógenos, dilatando-se no momento do parto. A vulva e a vagina permitem a passagem do sêmen para sua deposição, além de proteger os espermatozóides contra a dessecação e contaminação excessiva com micro-organismos. A vagina tem como função reduzir a contaminação da cérvix, principalmente durante a gestação, assim como servir como porta para o feto no momento do parto (FOSTER, 2013).

\section{ANOMALIAS ASSOCIADAS À DIFERENCIAÇÃO SEXUAL}

\section{Hermafroditas verdadeiros}

É uma condição bastante rara. Os animais acometidos por esta anomalia são indivíduos com tecido testicular e ovariano ou combinados em uma única gônada (ovotestis) ou existentes em gônadas separadas (BEARDEN; FUQUAY, 2000; SCHLAFER; FOSTER, 2015). hermafroditismo é classificado em lateral (presença de um ovário e um testículo), unilateral (presença de ovário e ovotestis ou testículo e ovotestis) e bilateral (presença de dois 
ovotestis) (DAMIANI, 2001). Hermafroditas verdadeiros são estéreis e fenotipicamente as fêmeas têm sinais de masculinização. Esta alteração pode ser observada em cães Cocker Spaniel (reversão sexual XX) e outras raças com características autossômicas recessivas (FOSTER, 2013; NASCIMENTO; SANTOS, 2003; SHORT et al., 2016).

\section{Pseudo-hermafroditas}

Possuem apenas um tipo de tecido gonadal, e os sexos cromossômico e gonadal são concordantes (MEYERS-WALLEN, 2001); são classificados como femininos ou masculinos, conforme o tipo de gônoda presente (BEARDEN; FUQUAY, 2000). Pseudo-hermafroditas fêmeas possuem ovários, mas apresentam algum grau de masculinização. Já pseudohermafroditas machos apresentam testículos, porém possuem características femininas, como a presença de útero ou genitália externa primariamente feminina (MICKELSEN; MEMON, 1997).

Uma forma de pseudo-hermafroditismo masculino é a síndrome da feminilização testicular, na qual os animais não produzem testosterona ou não possuem receptores para este hormônio, e consequentemente não há o desenvolvimento da genitália externa (FOSTER, 2013; NASCIMENTO; SANTOS, 2003; SCHLAFER; FOSTER, 2015). Há relato de pseudohermafroditismo em três animais da raça Pit Bull (PRESTES et al., 2005). Cães da raça Schnauzer miniatura com ductos müllerianos persistentes apresentam o sistema mülleriano completo, porém não apresentam substâncias inibidoras müllerianas ou seus receptores (FOSTER, 2013).

\section{Quimerismo e Mosaico}

Apresentam órgãos reprodutivos ambíguos. Ambos apresentam dois ou mais tipos celulares, cada um com composição cromossômica diferente (FOSTER, 2013). As células de uma quimera são provenientes de duas fontes diferentes. Já em um mosaico as células são provenientes de uma única fonte. A condição de mosaico ocorre em gatos machos três cores ou malhados (FOSTER, 2013; WINTER; PFEFFER, 1977). 


\section{ANOMALIAS DA FORMAÇÃO E DO DESENVOLVIMENTO GONADAL FEMININO}

\section{Agenesia ovariana}

Pode envolver um ou ambos os ovários, ocorrendo raramente em cães. Quando bilateral a genitália externa permanece com aparência infantil (FOSTER, 2013; SCHLAFER; FOSTER, 2015). Agenesia ovariana unilateral foi descrita por Freitas et al. (2010) e Faria et al. (2011) em gatas sem raças definidas e adultas.

\section{Síndrome do ovário remanescente}

É caracterizada pela presença de tecido ovariano funcional no interior da cavidade abdominal (SCHIOCHET et al., 2007) e se desenvolve em cadelas e gatas castradas, as quais voltam a entrar no cio. A causa mais comum desta anomalia é a remoção incompleta dos ovários durante a castração (FOSTER, 2013; SCHLAFER; FOSTER, 2015).

\section{Hipoplasia ovariana}

Pouco frequente em animais de companhia (NASCIMENTO; SANTOS, 2003). É usualmente bilateral, porém não simétrica. Os ovários são pequenos e não possuem folículos ou cicatrizes de ovulação; a genitália externa permanece com aparência infantil (SCHLAFER; FOSTER, 2015).

\section{Cistos ovarianos}

São comuns em diversas espécies, principalmente em cadelas e gatas. Podem estar localizados no interior dos ovários e/ou no exterior do órgão. Os cistos exteriores são agrupados como cistos paraovarianos (SCHLAFER; FOSTER, 2015), e surgem dos ductos paramesonéfricos ou ductos e túbulos mesonéfricos (FOSTER, 2013). A localização e os nomes das anomalias císticas incidentais comuns encontram-se na Tabela 1. 
Tabela 1 - Cistos do trato reprodutivo feminino de cadelas e gatas conforme a localização.

\begin{tabular}{|c|c|c|c|}
\hline Cisto & & Origem & Espécie \\
\hline \multirow[t]{3}{*}{ Intraovariano } & Rete ovarii cística & Túbulo mesonéfrico & $\begin{array}{l}\text { Cadela e } \\
\text { gata }\end{array}$ \\
\hline & $\begin{array}{l}\text { Estrutura de } \\
\text { subsuperfície epitelial }\end{array}$ & $\begin{array}{l}\text { Invaginação normal do } \\
\text { epitélio ovariano }\end{array}$ & Cadela \\
\hline & $\begin{array}{l}\text { Cistoadenoma, } \\
\text { cistoadenocarcinoma }\end{array}$ & $\begin{array}{l}\text { Rete ovarii, estrutura } \\
\text { da subsuperfície } \\
\text { epitelial, superfície epitelial }\end{array}$ & $\begin{array}{l}\text { Cadela e } \\
\text { gata }\end{array}$ \\
\hline Paraovariano & $\begin{array}{l}\text { Cistos dos ductos } \\
\text { mesonéfricos }\end{array}$ & Ductos mesonéfricos & Cadela \\
\hline \multirow[t]{3}{*}{ Uterino } & $\begin{array}{l}\text { Cisto de inclusão da } \\
\text { serosa }\end{array}$ & Mesotélio da serosa & Cadela \\
\hline & Adenomiose & Endométrio & $\begin{array}{l}\text { Cadela e } \\
\text { gata }\end{array}$ \\
\hline & $\begin{array}{l}\text { Hiperplasia endometrial } \\
\text { cística }\end{array}$ & Endométrio/endometrite & $\begin{array}{l}\text { Cadela e } \\
\text { gata }\end{array}$ \\
\hline
\end{tabular}

\section{Hipoplasia de cérvix}

É a ausência de alguns anéis cervicais. Pode dificultar o fechamento funcional do canal e predispor a invasão do útero por micro-organismos patógenos e à endometrite crônica (SCHLAFER; FOSTER, 2015).

\section{Agenesia de cérvix}

Caracteriza-se pela ausência total dos anéis cervicais. É uma anomalia rara em pequenos animais. Raramente altera a fertilidade e a capacidade gestacional do animal, o que dificulta o diagnóstico (SANT'ANA et al., 2013).

\section{Agenesia uterina}

Geralmente ocorre a ausência completa de um dos cornos uterinos (PINTO FILHO et al., 2001; SCHLAFER; FOSTER, 2015). A agenesia unilateral do corno uterino, também denominada de útero unicórnio, é a alteração uterina congênita mais comum e resulta do 
desenvolvimento anômalo do ducto paramesonéfrico. Pode estar associada à agenesia unilateral renal, uma vez que ambos possuem a mesma origem embrionária (PINTO FILHO et al., 2001). Há relatos de aplasia segmentar do corpo uterino em cadelas (ALMEIDA et al., 2010; VINCE et al., 2011) e em gatas (CHANG et al., 2008).

\section{LESÕES OVARIANAS ADQUIRIDAS}

\section{Cistos de inclusão serosos}

Ocasionalmente observados em cadelas pluríparas. Os cistos formam-se de pequenas dobras de peritônio que se aderem e geram pequenos cistos de epitélio seroso aprisionado, os quais lentamente acumulam os fluidos secretados. Apresentam paredes finas translúcidas com fluido claro no interior (SCHLAFER; FOSTER, 2015). Estes cistos variam conforme o tamanho podendo medir desde milímetros a vários centímetros. Podem ocorrer durante a involução uterina ou em associação com perimetrite (FOSTER, 2013; SCHLAFER; FOSTER, 2015).

\section{Cistos hemorrágicos}

Hemorragias no interior de cistos foliculares podem ocorrer em cadelas. Uma mínima hemorragia confinada à cavidade folicular ocorre no momento da ovulação em todas espécies (FOSTER, 2013; SCHLAFER; FOSTER, 2015).

\section{Cistos anovulatórios}

Cistos anovulatórios de ambos os tipos, folicular e luteinizado, tendem a ocorrer em faixas etárias mais avançadas. Eles tendem a serem múltiplos e geralmente tem luteinização parcial da parede dos cistos (SCHLAFER; FOSTER, 2015).

\section{Ovário policístico}

Raramente ocorre em cadelas, podendo ocorrer em nulíparas e multíparas (SCHLAFER; FOSTER, 2015). Pode acometer um ou ambos os ovários, sendo que o ovário afetado apresenta cistos de paredes finas que variam de 1 a $12 \mathrm{~mm}$ de diâmetro (FOSTER, 2013; SCHLAFER; FOSTER, 2015). 


\section{LESÕES UTERINAS E ENDOMETRIAIS ADQUIRIDAS}

\section{Torção uterina}

A torção uterina é pouco frequente em cães e gatos, sendo mais descrita em gatos (SILVA, 2008). Pode ocorrer em fêmeas gestantes ou ser consequência de piometra e hidrometra (FOSTER, 2013). O ponto fixo uterino é o mesovário, com outro ponto fixo influenciado pelo comprimento dos cornos uterinos e pela rigidez dos ligamentos entre os cornos (SCHLAFER; FOSTER, 2015). A torção geralmente ocorre ao redor do mesométrio e acontece na junção entre os cornos e o corpo uterino. Em consequência, há infarto venoso, congestão e edema da parede uterina e da placenta (FOSTER, 2013; RIDYARD et al., 2000; SCHLAFER; FOSTER, 2015).

\section{Prolapso uterino}

Raramente ocorre em cadelas e gatas (GRUNDY, 1980; ÖZYURTLU; KAYA, 2005). Pode acometer primíparas e multíparas, acometendo um ou ambos os cornos uterinos (LEAL et al., 2003). Suas causas são desconhecidas. Fatores que causam inércia uterina como um parto prolongado (48 horas), quando a cérvix se encontra dilatada e condições de hipocalcemia são predisponentes ao prolapso uterino (FOSTER, 2013). Com o comprometimento vascular causado pelo prolapso, o tecido uterino apresenta-se congesto e edemaciado (FOSTER, 2013; NÖTHLING et al., 2002).

\section{Ruptura uterina}

Pode ocorrer espontaneamente ou por intervenções obstétricas. A ruptura completa muitas vezes pode ser fatal em virtude da hemorragia ou causar contaminação peritoneal (FOSTER, 2013; SCHLAFER; FOSTER, 2015).

\section{Distúrbios circulatórios}

Hiperemia e edema endometrial ocorrem normalmente no estro (JOHNSON, 2006) e podem atingir desenvolvimento relativo na cadela durante o pró-estro. A diapedese e esfoliação endometrial resultante representam a hemorragia uterina no pró-estro desta espécie. Pode ocorrer hemorragia devido a uma torção e inversão, além da ruptura da artéria uterina (SCHLAFER; FOSTER, 2015). 


\section{Atrofia de endométrio}

É o resultado da perda da função ovariana, geralmente secundária ao hipopituitarismo. Atrofia senil é incomum em animais domésticos (FOSTER, 2013; SCHLAFER; FOSTER, 2015).

\section{Hiperplasia endometrial}

Lesão importante em cadelas e gatas. É possível observar-se um espessamento leve, desigual ou generalizado do endométrio. Microscopicamente há o aumento no tamanho e número de glândulas, sem alterações no estroma com exceção do edema. O epitélio glandular apresenta uma aparência progestacional (FOSTER, 2013).

\section{Hiperplasia endometrial não cística}

Macroscopicamente não é reconhecível, exceto quando há espessamento do endométrio. Este espessamento deve-se ao aumento e número de glândulas, as quais estão distribuídas irregularmente (FOSTER, 2013). O estroma não se apresenta hiperplásico porém é edematoso. Em cadelas, as glândulas são tortuosas e secretoras com células epiteliais tipicamente progestacionais e hipertrofiadas. Geralmente observa-se algum grau de adenomiose (FOSTER, 2013; SCHLAFER; FOSTER, 2015).

\section{Hiperplasia segmentar}

A hiperplasia segmentar canina é incomum. Caracteriza-se pela proliferação das glândulas endometriais e a superfície endometrial assemelha-se aos locais de implantação de gestação (FOSTER, 2013; SCHLAFER; FOSTER, 2015).

\section{Adenomiose}

Esta lesão ocorre em cadelas e gatas, e consiste na presença de tecido endometrial no interior do miométrio. Macroscopicamente o útero sofre um aumento simétrico difuso ou assimétrico focal (FOSTER, 2013; SCHLAFER; FOSTER, 2015).

\section{Hidrometra e Mucometra}

São respectivamente o acúmulo de fluido claro (FOSTER, 2013; NASCIMENTO; SANTOS, 2003) e o acúmulo de muco no interior do útero (AGUIRRA et al., 2015; FOSTER, 2013). A obstrução congênita ou adquirida do fluxo de muco, inicialmente produzido em quantidade 
normal, pode causar estas lesões. O fluido acumula-se próximo à região obstruída. A mucometra ocorre durante a pseudogestação, com regressão espontânea, e em casos de hiperestrogenismo (FOSTER, 2013). Aguirra et al. (2015) descreveram a incidência de 9\% desta alteração na população estudada.

O acúmulo de fluido no útero é concomitante ao desenvolvimento de hiperplasia endometrial ou proximal a uma obstrução do lúmen cervical, uterino, ou vaginal. Caso a hidrometra ou mucometra persistam por longo tempo, o endométrio torna-se acentuadamente atenuado e pode atrofiar, e estas lesões contribuem para infertilidade (FOSTER, 2013; SCHLAFER; FOSTER, 2015).

\section{Pólipos endometriais}

São crescimentos localizados do estroma e das glândulas endometriais. Ocorrem comumente em cadelas e gatas velhas. Podem ser únicos ou múltiplos e caracterizam-se por serem nodulares com base estreita ou aumentados de volume. São de causa desconhecida, mas podem estar relacionados à idade (FOSTER, 2013; SCHLAFER; FOSTER, 2015).

\section{LESÕES ADQUIRIDAS DE CÉRVIX, VULVA E VAGINA}

\section{Estenose de cérvix}

A estenose de cérvix é extremamente rara e é uma alteração adquirida. Consiste na fusão de superfícies epiteliais com áreas escarificadas. Pode ocorrer devido à laceração severa ou inflamação crônica (SCHLAFER; FOSTER, 2015).

\section{Ruptura de vagina e vulva}

São lesões frequentemente adquiridas no parto. Pode ocorrer o rompimento da mucosa ou de toda parede vaginal (SCHLAFER; FOSTER, 2015).

\section{Tumefação de vulva}

É a resposta fisiológica a estrógenos. O aumento de volume da vulva pode ocorrer naturalmente durante o cio ou por exposição persistente a estrógenos endógenos e exógenos como plantas e anticoncepcionais. Concentrações anormais de estrógenos podem 
ocorrer por doença cística folicular, tumores secretórios de estrógenos ou de origem exógena (SCHLAFER; FOSTER, 2015).

\section{LESÕES INFLAMATÓRIAS OVARIANAS}

\section{Ooforite}

Consiste na inflamação dos ovários (FOSTER, 2013). É relativamente rara em animais domésticos e quando ocorre é usualmente piogênica. Pode ter etiologia bacteriana em cadelas e gatas, nas quais deve ser diferenciada de peritonite infecciosa felina (SCHLAFER; FOSTER, 2015).

\section{LESÕES INFLAMATÓRIAS DAS TUBAS UTERINAS, ÚTERO, ENDOMÉTRIO E CÉRVIX}

\section{Hidrossalpingite}

É a distensão uniforme ou irregular da tuba uterina por um fluido claro, que se acumula devido à obstrução funcional ou mecânica do lúmen (FOSTER, 2013; NASCIMENTO; SANTOS, 2003; SCHLAFER; FOSTER, 2015). Pode ser congênita, associada a aplasia segmentar do corno uterino, ou adquirida, secundária a traumas ou inflamações crônicas (FOSTER, 2013; SCHLAFER; FOSTER, 2015).

\section{Salpingite}

Esta condição é o resultado da disseminação da infecção uterina para a tuba e é incomum nas espécies domésticas (FOSTER, 2013). É usualmente bilateral. As alterações macroscópicas são discretas e consistem de hiperemia, espessamento da mucosa e escasso exsudato no lúmen, que pode apresentar exsudato fibrinoso, catarral ou seroso. A salpingite pode culminar com periooforite, resultando em infertilidade (FOSTER, 2013; SCHLAFER; FOSTER, 2015). Grande parte dos casos de salpingite em cadelas são relacionados com o complexo hiperplasia endometrial cística - piometra (NASCIMENTO; SANTOS, 2003). É uma lesão comumente observada em animais infectados por Mycoplasma sp. e Ureaplasma sp. A salpingite granulomatosa é incomum e quando ocorre, a tuba uterina apresenta-se firme e distendida (FOSTER, 2013; SCHLAFER; FOSTER, 2015). 


\section{Piossalpingite}

Ocorre o acúmulo de exsudato purulento no lúmen da tuba, evoluindo para a obstrução deste (FOSTER, 2013). Os micro-organismos que podem causar a piossalpingite são Streptococcus sp., Staphylococcus sp., Escherichia coli e Trueperella pyogenes, sendo este último o patógeno mais comum e importante. O resultado desta lesão é a erosão e subsequente granulação ou metaplasia escamosa do epitélio (SCHLAFER; FOSTER, 2015).

\section{Endometrite}

Refere-se a inflamação restrita ao endométrio. Grande parte das infecções uterinas iniciam como endometrite, podendo progredir e envolver o miométrio (SCHLAFER; FOSTER, 2015). Ocorre normalmente por infecção bacteriana em úteros não gestantes. As formas mais brandas são observadas pós-coito e casos leves são dificilmente detectados. Em cadelas e gatas, podem colaborar para a formação de hiperplasia endometrial cística. Os patógenos que causam placentite, infecção fetal e aborto podem invadir o endométrio e causar inflamação. Em casos mais acentuados, observa-se mucosa edemaciada e com superfície rugosa com filamentos de fibrina e restos celulares (FOSTER, 2013; SCHLAFER; FOSTER, 2015).

\section{Metrite}

A metrite é a inflamação de todas as camadas da parede uterina (NASCIMENTO; SANTOS, 2003; SCHLAFER; FOSTER, 2015). Decorre da progressão da endometrite (FOSTER, 2013). Quando na fase aguda, a serosa apresenta-se escurecida, finamente granular com hemorragia petequial e com feixes de fibrina aderidos. A parede uterina encontra-se espessada, com sufusões e edema. A secreção pode ser escassa ou abundante, de coloração amarelada a vermelha-escura e fétida (FOSTER, 2013; SCHLAFER; FOSTER, 2015).

\section{Complexo hiperplasia endometrial cística (CHEC) - piometra}

Usualmente envolve o aumento cístico das glândulas endometriais (SCHLAFER; FOSTER, 2015). A hiperplasia endometrial cística está correlacionada a altos níveis de estrógenos e exposição prolongada de progesterona endógena ou exógena (FOSTER, 2013; JOHNSON, 2006; NASCIMENTO; SANTOS, 2003). Ao sofrer influência hormonal pode haver proliferação 
excessiva das glândulas endometriais e formação de cistos. É um dos fatores predisponentes para que ocorra hidrometra, mucometra e piometra (FELDMAN; NELSON, 1987; SCHLAFER; FOSTER, 2015).

A piometra ocorre como sequela da endometrite ou metrite. É a infecção aguda ou crônica do útero com acúmulo de pus no lúmen (DOW, 1957; SCHLAFER; FOSTER, 2015). A contaminação bacteriana do fluido ocorre por via ascendente, provavelmente da flora vaginal. Grande parte dos casos de piometra estão associados à hiperplasia endometrial cística (FELDMAN; NELSON, 1987; FOSTER, 2013; JOHNSON, 2006; SCHLAFER; FOSTER, 2015).

O complexo hiperplasia endometrial cística - piometra é a alteração mais comum dentre as afecções proliferativas não neoplásicas uterinas (FOSTER, 2013; JOHNSON, 2006; SCHLAFER; FOSTER, 2015) e é uma patologia de grande importância em cadelas (FOSTER, 2013; GOERICKE-PESCH et al., 2010; JOHNSON, 2006; PRETZER, 2008; SCHLAFER; FOSTER, 2015) e gatas (KENNEY et al., 1987; TONIOLLO et al., 2000). Ocorre principalmente no diestro, momento em que corpos lúteos estão presentes e os níveis de progesterona estão elevados (FELDMAN; NELSON, 1987; JOHNSON, 2006).

A piometra ocorre principalmente em cadelas em idade reprodutiva e o risco de desenvolvimento desta patologia aumenta com a idade, provavelmente devido à repetida estimulação hormonal no útero. Em felinos, esta patologia é menos frequente, pois o desenvolvimento do tecido luteal exige cópula (FELDMAN; NELSON, 1987; SCHLAFER; FOSTER, 2015; TONIOLLO et al., 2000). Gatas tratadas com progestágenos contra dermatopatias tendem a desenvolver piometra (FOSTER, 2013). Nos casos mais brandos, o útero pode estar ligeiramente aumentado com hiperplasia endometrial e inflamação. Em gatas de vida livre a piometra foi observada em 0,4\% (JOHNSON, 2006).

Há risco elevado associado à nulíparas. Raças como Golden Retriever, Schnauzer miniatura, Terrier escocês, São Bernardo, Border Collie, Rottweiler, entre outras, apresentam alta incidência para CHEC (SMITH, 2006). Por outro lado, fêmeas sem raça definida e Daschshund apresentam menor predisposição para a patologia (NISKANEN; THURSFIELD, 1998).

Em casos avançados, há marcada distensão dos cornos uterinos ocupando grande parte da cavidade abdominal (FOSTER, 2013). A superfície serosa uterina apresenta-se enegrecida, 
necrótica, ulcerada e hemorrágica, com vasos hiperêmicos e congestos. A parede encontrase friável e pode ocorrer ruptura ou perfuração uterina causando, então, peritonite (FOSTER, 2013; SCHLAFER; FOSTER, 2015). Áreas císticas, espessadas, brancas e secas também podem ser observadas. A piometra é classificada de acordo com o padrão de fechamento da cérvix, em aberta (com corrimento vulvar) ou fechada (sem corrimento vulvar) (Figura 1) (FELDMAN; NELSON, 1987).

Quando há infecção por Escherichia coli e Proteus spp., a lesão é severa e o exsudato é vermelho-amarronzado, espesso, viscoso, opaco e fétido (JOHNSON, 2006; SCHLAFER; FOSTER, 2015). Em outros casos quando a infecção se dá por Streptococcus sp. e Staphylococcus sp. o exsudato geralmente é purulento (FOSTER, 2013; JOHNSON, 2006; SCHLAFER; FOSTER, 2015).

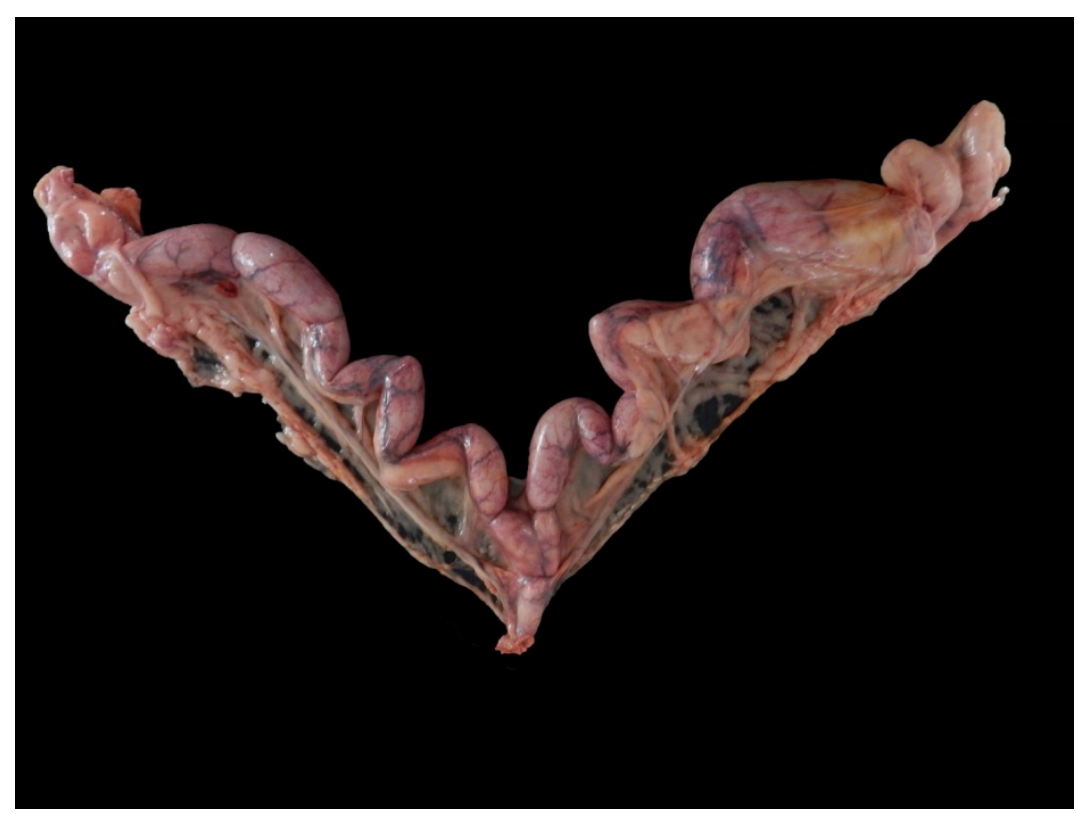

Figura 1 - Cornos uterinos aumentados e vasos ectásicos (piometra) (Fonte: arquivo pessoal).

\section{Abscesso uterino}

Raramente ocorre em animais domésticos. Caracteriza-se pela localização da infecção em uma parte do útero, que provém de uma metrite ou de uma injúria traumática focal no endométrio infectado (FOSTER, 2013). Os abscessos são geralmente bem encapsulados, atingindo até $15 \mathrm{~cm}$ de diâmetro. Pode haver aderência perimetrial, e em alguns casos 
ruptura para a cavidade abdominal ou vísceras ocas adjacentes (FOSTER, 2013; SCHLAFER; FOSTER, 2015).

\section{Perimetrite e Parametrite}

Consistem na inflamação da serosa e na inflamação dos ligamentos suspensórios do útero, respectivamente (FOSTER, 2013; SCHLAFER; FOSTER, 2015).

\section{Cervicite}

É a extensão da endometrite ou vaginite (NASCIMENTO; SANTOS, 2003; SCHLAFER; FOSTER, 2015). Esse processo é caracterizado por hiperemia, edema, projeção dos primeiros anéis cervicais para a vagina e exsudato mucopurulento (NASCIMENTO; SANTOS, 2003).

\section{NEOPLASMAS OVARIANOS}

Geralmente, os tumores ovarianos de cadelas são epiteliais e bilaterais, com incidência de um a seis por cento em animais de cinco a 15 anos, sendo os tumores da granulosa os mais frequentes nessa faixa etária, e os teratomas em cadelas jovens (SFORNA et al., 2003).

Neoplasmas ovarianos são raros em cães e gatos (PARK et al., 2008; SCHLAFER; FOSTER, 2015). São conhecidos três grupos de neoplasmas ovarianos primários: das células germinativas, dos cordões sexuais do estroma e os epiteliais. Estes representam as principais origens histogênicas (FOSTER, 2013).

Os neoplasmas de células germinativas geralmente dividem-se em duas categorias: o disgerminoma e o teratoma (FOSTER, 2013; SCHLAFER; FOSTER, 2015). O disgerminoma é um tumor raro, benigno e indiferenciado, que acomete cadelas e caracteriza-se por apresentar células semelhantes às germinativas primitivas (JACSON et al., 1985; SCHLAFER; FOSTER, 2015). Macroscopicamente é observado como uma massa sólida lobulada com áreas de hemorragia e necrose. Usualmente é unilateral e apresenta padrão de crescimento difuso (SCHLAFER; FOSTER, 2015). Este neoplasma é análogo ao seminoma, que ocorre em machos (FOSTER, 2013; JACSON et al., 1985). Apesar da taxa de mitose ser alta, metástases são raras, ocorrendo em até 20\% dos casos (SCHLAFER; FOSTER, 2015). 
O teratoma ovariano, apesar de raro, tem sido relatado em cadelas. Geralmente de caráter benigno e bem diferenciado (FOSTER, 2013; SCHLAFER; FOSTER, 2015). Este neoplasma surge das células germinativas primordiais totipotentes, apresentando elementos desorganizados de pelo menos duas das três camadas germinativas embrionárias como tecido neural, adiposo, ósseo, pelos, dentes e epitélio respiratório. A variante maligna do teratoma também pode ocorrer em cadelas (SCHLAFER; FOSTER, 2015).

Dentre os neoplasmas do estroma gonadal, o tumor das células da granulosa é o mais comum, principalmente em animais de produção (FOSTER, 2013). Usualmente são benignos em todas as espécies e sua incidência aumenta com a idade, apesar de ter sido também observado em animais jovens (FOSTER, 2013; NASCIMENTO; SANTOS, 2003). Em cadelas e, menos frequentemente, em gatas, os neoplasmas das células da granulosa tendem a ser malignos. São unilaterais, com superfície macia e redonda, podendo atingir 20 a $30 \mathrm{~cm}$ de diâmetro, podendo ser sólidos, císticos ou policísticos (FOSTER, 2013; SCHLAFER; FOSTER, 2015). O conteúdo cístico é geralmente vermelho-amarronzado. Grande parte das cadelas que desenvolvem estes neoplasmas apresenta CHEC - piometra. Microscopicamente, em gatas, podem ser observados corpúsculos de Call Exner (FOSTER, 2013; NASCIMENTO; SANTOS, 2003).

Os luteomas ou tecomas são menos comuns em animais domésticos e provavelmente surgem das células da granulosa ou da teca. São firmes e de coloração branco-alaranjada (FOSTER, 2013; NASCIMENTO; SANTOS, 2003).

Dentre os neoplasmas epiteliais, os epiteliais celomáticos ocorrem apenas em cadelas (SCHLAFER; FOSTER, 2015). Cistoadenomas serosos papilares e cisto-adenocarcinomas serosos são comumente relatados em cadelas (FOSTER, 2013). Assim como no tumor das células da granulosa, grande parte das cadelas que desenvolvem estes tumores apresenta hiperplasia endometrial cística (FOSTER, 2013; SCHLAFER; FOSTER, 2015).

A origem destes neoplasmas pode ser do epitélio superficial ou de restos subsuperficias de ovário, ou na rete ovarii. Estes tumores frequentemente são bilaterais, apresentam superfície irregular e podem chegar a aproximadamente $10 \mathrm{~cm}$ diâmetro (SCHLAFER; FOSTER, 2015). 
O ovário ainda pode ser acometido por tumores de tecidos não gonadais. O hemangioma ovariano é pouco frequente em animais domésticos. Surge do córtex ovariano e geralmente é bilateral (SCHLAFER; FOSTER, 2015). Apesar de infrequentes, os leiomiomas são relatados em gatas e cadelas, e se desenvolvem do músculo liso do mesovário. Ainda ocorrem tumores secundários de ovário como linfomas e carcinomas mamários (FOSTER, 2013; SCHLAFER; FOSTER, 2015).

\section{NEOPLASMAS DE ÚTERO, VAGINA E CÉRVIX}

Os leiomiomas são neoplasmas primários que se desenvolvem com relativa frequência em cadelas (KENNEDY et al., 1998; MACLACHLAN; KENNEDY, 2002). Originam-se tecido muscular liso do útero, vagina ou cérvix e usualmente são múltiplos, não se limitando ao útero. É possível que o estrógeno desempenhe um papel na causa e na manutenção desta neoplasia em cadelas (FOSTER, 2013; SILVA et al., 2004).

Outro importante neoplasma do trato genital de cães é o tumor venéreo transmissível (TVT). Trata-se de um neoplasma contagioso, constituído por células redondas (CHU et al., 2001; FOSTER, 2013; MACLACHLAN; KENNEDY, 2002). Pode acometer cães, coiotes, lobos e raposas (ORTEGA-PACHECO et al., 2003). Cães errantes, de ambos os sexos são os mais afetados (TINUCCI-COSTA, 2009). É transmitido normalmente pelo coito, ou mecanicamente através da lambedura, mordedura e arranhões (HUPPES et al., 2014). Para o desenvolvimento do tumor é necessário que a pele ou mucosa apresentem solução de continuidade ou escoriações (COHEN, 1980; DAS; DAS, 2000).

O TVT pode ter localização genital, com envolvimento da vagina, vulva e tubas uterinas, ou extragenital, quando acomete cavidade nasal, bucal e pele (FOSTER, 2013; HUPPES et al., 2014). Ocorre com maior frequência na vagina (53\% dos casos), vulva (33\%) e região extragenital (14\%) (RIBEIRO; ZAPPA, 2008). Apresenta aspecto peduncular, nodular, papilar ou multilobular, de consistência macia a firme, podendo ser único ou múltiplo, de diâmetro variável ( $5 \mathrm{~mm}$ a mais de $10 \mathrm{~cm}$ ). A superfície pode conter alterações adicionais que incluem inflamação, úlceras, necrose ou contaminação bacteriana (ROGERS et al., 1998). O neoplasma apresenta coloração branco-acinzentada a avermelhada devido à intensa vascularização (FOSTER, 2013). De acordo com a expressão morfológica do tipo celular 
predominante e o grau de agressividade, o TVT pode ser classificado em infocitóide e plasmocitóide. O padrão plasmocitóide apresenta morfologia ovóide, citoplasma mais abundante com núcleo excêntrico enquanto que o padrão linfocitóide apresenta morfologia arredondada, citoplasma escasso e finamente granular com presença de vacúolos que acompanha a periferia da célula, núcleo central e redondo com cromatina grosseira e presença de um ou dois nucléolos salientes (AMARAL, 2005).

Metástases são raras, sendo descritas em aproximadamente 5\% dos casos. Podem ocorrer nos linfonodos regionais, rins, baço, olhos, cérebro, hipófise, pele, tecido subcutâneo e peritônio (FERNANDES et al., 2013; MUNDIM et al., 1987; RICHARDSON, 1981).

Outros tumores primários raros foram descritos no útero, cérvix e vagina, tais como o carcinoma de endométrio, carcinoma de cérvix e linfossarcoma (FOSTER, 2013; SCHLAFER; FOSTER, 2015).

\section{CONCLUSÃO}

Existem diversas patologias do sistema genital feminino em cadelas e gatas, as mais frequentes são o complexo hiperplasia endometrial cística - piometra e as neoplasias ovarianas.

\section{PATHOLOGIES OF THE FEMALE GENITAL SYSTEM OF DOGS AND CATS}

\section{ABSTRACT}

\footnotetext{
C onsidering the survival of a species, the reproductive system is one of the most important systems. The undifferentiated gonads are formed by germ cells that differentiate in testicles when stimulated by testicular differentiation factor, or in ovaries when unstimulated. Here injuries of sexual development and anomalies of the female gonadal formation and development will be approached. Among the studied pathologies are the cystic endometrial hyperplasia - pyometra complex, metritis, ovarian and uterine neoplasms.
}

Keywords: Female genital system. Cystic endometrial hyperplasia - pyometra complex. Female dog. Female cat. 


\section{PATOLOGÍAS DEL SISTEMA GENITAL FEMENINO DE LOS PERROS Y GATOS}

\section{RESUMEN}

E n vista de la supervivencia de una especie, el sistema reproductivo es uno de los sistemas más importantes. Las gónadas indiferenciadas se forman por las células madre que cuando estimuladas por el factor de diferenciación testicular se diferencian en testículos, o cuando no estimuladas, en ovarios. Aquí se tratará las lesiones del desarrollo sexual y anomalías de la formación y el desarrollo de las gónadas femeninas. Entre las condiciones que se abordan son los complejo hiperplasia quística endometrial - piómetra, metritis, tumores de ovario y de útero.

Palabras clave: Sistema genital femenino. Complejo hiperplasia quística endometrial piómetra. Perra. Gata.

\section{REFERÊNCIAS}

AGUIRRA, L. R. V. M.; PEREIRA, W. L. A.; MARSOLLA, E. H. Ocorrência e aspectos macro e microscópicos da mucometra em cadelas. Veterinária e Zootecnia, v. 22, n. 1, p. 83-88, 2015.

ALMEIDA, M. V. D.; REZENDE, E. P.; LAMOUNIER, A. R.; RACHID, M. A.; NASCIMENTO, E. F.; SANTOS, R. L.; VALLE, G. R. Aplasia segmentar de corpo uterino em cadela sem raça definida: relato de caso. Arquivo Brasileiro de Medicina Veterinária e Zootecnia, v. 62, n. 4, p. 797$800,2010$.

AMARAL, A. S. Tumor venéreo transmissível canino: critérios citológicos de malignidade e caracterização citomorfológica correlacionada a imunocitoquímica e lesões de DNA. Botucatu: UNESP, 2005, 228p. Tese (Doutorado em Medicina Veterinária), Faculdade de Medicina Veterinária e Zootecnia, Universidade Estadual Paulista, 2005.

BEARDEN, H. J.; FUQUAY, J. W. Applied Animal Reproduction. 5. ed. Pearson, 2000. 400p.

CHANG, J.; JUNG, J.; YOON, J; CHOI, M.; PARK, J. H.; SEO, K.; JEONG, S. M. Segmental aplasia of the uterine horn with ipsilateral renal agenesis in a cat. The Journal of Veterinary Medical Science, v. 70, n. 6, p. 641-643, 2008.

CHU, R. M.; SUN, T. J.; YANG, H.; WANG, D. G.; LIAO, L. W.; CHUANG, T. F.; LIN, C. H.; LEE, W. C. Heat shock proteins in canine transmissible venereal tumor. Veterinary Immunology and Immunopathology, v. 82, n. 1-2, p. 9-21, 2001. 
COHEN, D. In vitro cell-mediated cytoxicity and antibody-dependent cellular cytoxicity to the transmissible veneral tumor of the dog. Journal of the National Cancer Institute, v. 64, n. 2, p. 317-321, 1980.

DAMIANI, D.; SETIAN, N.; KUPERMAN, H. Genitália Ambígua: Diagnóstico Diferencial e Conduta. Arquivo Brasileiro Endocrinologia e Metabologia, v. 45, p. 37-48, 2001.

DAS, U.; DAS, A. K. Review of canine transmissible veneral sarcoma. Veterinary Research Communications, Dordrecht, v. 24, n. 8, p. 545-556, 2000.

DOW, C. The cystic hyperplasia-pyometra complex in the bitch. Veterinary Record, v. 69, p. 1409-1414, 1957.

FARIA, J. A.; ALVES, N. D.; FEIJÓ, F. M. C.; AMORA, S. S. A.; SARAIVA, M. N. R.; SARAIVA, J. C. R.; RIBEIRO, G. T.; AMORIM, A. S.; ROSAS, N. S. C. Agenesia unilateral ovariana em gata: relato de caso. In: CONGRESSO BRASILEIRO DE MEDICINA VETERINÁRIA, 38, 2011, Florianópolis. ANAIS. Florianópolis, SBMV/SOMEVESC, 2011. Disponível em: <http://www.sovergs.com.br/site/38conbravet/resumos/437.pdf>

FELDMAN, E. C; NELSON, R. W. Canine and feline endocrinology and reproduction. Philadelphia: W. B. Saunders, 1987. 785p.

FERNANDES, C. P. M.; GASPAR, L. F. J.; MEINERZ, A. R. M.; GRECCO, F. B.; NOBRE, M. O.; CLEFF, M. B. Tumor venéreo transmissível canino com metástase encefálica. Semina: Ciências Agrárias, v. 34, n. 6, suplemento 2, p. 3929-3934, 2013.

FOSTER, R. A. Sistema Reprodutivo da Fêmea. In: McGAVIN, M. D.; ZACHARY, J. F. Bases da Patologia Veterinária. 5. ed. Rio de Janeiro: Elsevier, 2013. P. 1088-1099.

FREITAS, A. L.; REGO, R. O.; ROCHA, M. O. C.; SILVA, T. M. F.; QUEIROZ, G. F.; PAULA, V. V.; FILGUEIRA, K. D. Síndrome do ovário remanescente em uma gata doméstica. Acta Veterinaria Brasilica, v. 4, n. 2, p. 118-122, 2010.

GOERICKE-PESCH, S.; SCHMIDT, B.; FAILING, K.; WEHREND, A. Changes in the histomorphology of the canine cervix though the oestrus cycle. Theriogenology, v. 74, n. 6, p. 1075-1081, 2010.

GRUNDY, A. M. Partial uterine prolapse in a bitch. Veterinary Record, v. 106, n. 18-20, p. 420-421, 1980.

HUPPES, R. R.; SILVA, C. G.; USCATEGUI, R. A. R.; NARDI, A. B.; SOUZA, F. W.; TINUCCI-COSTA, M.; AMORIM, R. L.; PAZZINI, J. M.; FARIA, J. L. Tumor venéreo transmissível (TVT): estudo retrospectivo de 144 casos. Ars Veterinaria, v. 30, n. 1, p. 13-18, 2014. 
JACSON, M. L.; MILLS, J. H. L.; FOWLER, J. D. Ovarian dysgerminoma in a bitch. Case report. Canadian Veterinary Journal, v. 26, n. 9, p. 285-287, 1985.

JOHNSON, C. A. Distúrbios do sistema reprodutivo. In: NELSON, R. W.; COUTO, C. G. Medicina Interna de Pequenos Animais. 3. ed. Rio de Janeiro: Elsevier, 2006. P. 811-912.

KENNEDY, P. C.; CULLEN, J. M.; EDWARDS, J. F.; GOLDSCHMIT, M. H.; LARSEN, S.; MUNSON, L. Histological classification of tumors of the genital system of domestic animals. 2. ed. Washington: Armed Dorces Institute of Pathology, 1998.

KENNEY, K. J.; MATTHIESEN, D. T.; BROWN, N. O.; BRADLEY, R. L. Pyometra in cats: 183 cases (1979-1984). Journal of the American Veterinary Medical Association, v. 191, n. 9, p. 11301132, 1987.

LEAL, L. S.; OBA, E.; PRESTES, N. C.; BICUDO, S. D. Prolapso uterino em gata: relato de três casos. Clínica Veterinária, n. 46, p. 56-58, 2003.

MACLACHLAN, N. J.; KENNEDY, P. C. Tumor of the genital systems. In: MEUTEN D. J. (Ed.), Tumors in Domestic Animals. 4. ed. lowa: State Press, 2002. P. 547-573.

MEYERS-WALLEN, V. N. Anormalidades heredadas del desarrollo sexual en perros y gatos. In: CONCANNON, P. W.; ENGLAND, G.; VERSTEGEN, J. (Eds). Recent Advances in Small Animal Reproduction. New York: International Veterinary Information, 2001.

MICKELSEN, W. D.; MEMON, M. A. Distúrbios hereditários e congênitos dos sistemas reprodutivos do macho e da fêmea. In: ETTINGER, S. J.; FELDMAN, E. C. Tratado de medicina interna. Moléstias do cão e gato. 4. ed. São Paulo: Manole, v. 2, 1997. P. 2326-2331.

MUNDIM, A. V.; FERREIRA, P. A. S.; SANTOS, M. J. Tratamento de tumor de Sticker cutâneo em cães pela vincristina. Revista do Centro de Ciências Biomédicas da Universidade Federal de Uberlândia, v. 3, n. 1, p. 63-65, 1987.

NASCIMENTO, E. F.; SANTOS, R. L. Patologia da Reprodução dos Animais Domésticos. 2. ed. Rio de Janeiro: Guanabara Koogan, 2003.

NISKANEN, M.; THRUSFIELD, M. V. Associations between age, parity, hormonal therapy and breed, and pyometra in Finnish dogs. Veterinary Record, v. 143, n. 18, p. 493-498, 1998.

NÖTHLING, J. O.; KNESL, O.; IRONS, P. Uterine prolapse with an interesting vascular anomaly in a cheetah: a case report. Theriogenology, v. 58, n. 9, p. 1705-1712, 2002.

ORTEGA-PACHECO, A.; ACEVEDO-ARCIQUE, M.; SAURI-ARCEO, C.; BOLIO-GONZÁLEZ, M.; BLANCO, E. G. Prevalência de tumor venéreo transmisible en perros callejeros de la ciudad de Mérida, Yucatán, México. Revista Biomédica, v. 14, n. 2, p. 83-87, 2003. 
ÖZYURTLU, N.; KAYA, D. Unilateral uterine prolapse in a cat. Turkish Journal of Veterinary and Animal Sciences, v. 29, p. 941-943, 2005.

PARK, J. K.; GOO, M. J.; HONG, I. H.; KI, M. R.; HAN, J. Y.; JEONG, K. S. Immunohistochemistry diagnosis of an ovarian dysgerminoma in one bitch. Reproduction in Domestic Animals, v. 44, n. 5 , p. $855-858,2008$.

PINTO FILHO, S. T. L.; CUNHA, O.; RAISER, A. G.; BARBOSA, G. S.; PORTELLA, L. C. V.; IRIGOYEN, L. F. Agenesia unilateral de corno uterino de cadela-relato de caso. Arquivos de Ciências Veterinárias e Zoologia da UNIPAR, v. 4, n. 1, p. 77-79, 2001.

PRESTES, N. C.; LEAL, L. S.; JORGE, P.; DERUSSI, A. A. P.; MOTA, L. S. L. S.; OBA, E. Pseudohermafroditismo masculino canino-relato de três casos. Veterinária e Zootecnia, v. 12, n. 1/2, p. 14-19, 2005.

PRETZER, S. D. Clinical presentation of canine pyometra and mucometra: A review. Theriogenology, v. 70, n. 3, p. 359-363, 2008.

RIBEIRO, I.; ZAPPA, V. Tumor venéreo transmissível em cães. Revista Científica Eletrônica de Medicina Veterinária, v. 6, n. 11, p. 1-5, 2008.

RICHARDSON, R. C. Canine transmissible veneral tumor. Compendium on Continuing Education for the Practising Veterinarian, v. 3, n. 11, p. 951-956, 1981.

RIDYARD, A. E.; WELSH, E. A.; GUNN-MOORE, D. A. Successful treatment of uterine torsion in a cat with severe metabolic and haemostatic complications. Journal of Feline Medicine and Surgery, v. 2, n. 2, p. 115-119, 2000.

ROGERS, K. S., WALKER, M. A., DILLON, H. B. Transmissible venereal tumor: a retrospective study of 29 cases. Journal of the American Animal Hospital Association, v. 34, n. 6, p. 463470, 1998.

SANT 'ANA, J. L. P.; FELIPE, J. A.; ALVES, K. S.; MACHADO, J. P. Aplasia de Cérvix em Cadelarelato de caso. Anais V SIMPAC, v. 5, n. 1, p. 187-192, 2013.

SCHIOCHET, F.; BECK, C. F. C.; STEDILE, R.; FERREIRA, M. P.; CONTESINI, E.; ALIEVI, M. M.; SANTOS-JUNIOR, E. B.; BREISTSAMETER, I. Ovariectomia laparoscópica em uma gata com ovários remanescentes. Acta Scientiae Veterinariae, v. 35, n. 2, p. 245-248, 2007.

SCHLAFER, D. H.; FOSTER, R. A. Female Genital System. In: MAXIE, M. G. Jubb, Kennedy, and Palmer's Pathology of Domestic Animals. St. Louis: Elsevier, 2015. 6. ed., v. 3, p. 358-464.

SFORNA, M.; BRACHELENTE, C.; LEPRI, E.; MECHELLI, L. Canine ovarian tumours: a retrospective study of 49 cases. Veterinary Research Communications, v. 27, supp.1, 359361, 2003. 
SHORT, R. R.; MURAMOTO, C.; MACHADO, M. C. A.; MOREIRA, E. L. T.; RIBEIRO-FILHO, C. H. A.; NETO, F. A. D.; NETO, J. M. C. Hermafroditismo verdadeiro unilateral em cão-relato de caso. Revista Brasileira de Medicina Veterinária, v. 38, p. 17-25, 2016.

SILVA, A. E; SERAKIDES, R.; CASSALI, G. D. Carcinogênese hormonal e neoplasias hormôniodependentes. Ciência Rural, v. 34, n. 2, p. 625-633, 2004.

SILVA, S. B. Emergências do trato reprodutor feminino. In: SANTOS, M. M.; FRAGATA, F. S. Emergências e terapia intensiva veterinária em pequenos animais-bases para 0 atendimento hospitalar. São Paulo: Roca, 2008. P. 330-342.

SMITH, F. O. Canine pyometra. Theriogenology, v. 66, n. 3, p. 610-612, 2006.

TINUCCI-COSTA, M. T. Tumor venéreo transmissível canino. In: DALECK, C. R.; DE NARDI, A. B.; RODASKI, S. Oncologia em Cães e Gatos. São Paulo: Roca, 2009. Cap. 34, p. 540-551.

TONIOLLO, G. H.; FARIA-JUNIOR, D.; LEGA, E.; BATISTA, C. M.; NUNES, N. Piômetra na espécie felina-relato de um caso em Panthera onca. Brazilian Journal of Veterinary Research Animal Science, v. 37, n. 2, p. 166-168, 2000.

VINCE, S.; ZEVRNJA, B.; BECK, A.; FOLNOZIC, I.; GERES, D.; SAMARDZIJA, M.; GRIZEL, J.; DOBRANIC, T. Unilateral segmental aplasia of the uterine horn in a gravid bitch-case report. Veterinarski Arhiv, v. 81, n. 5, p. 691-698, 2011.

WINTER, H.; PFEFFER, A. Pathogenic classification of intersex. Veterinary Record, v. 100, n. 16, p. 307-309, 1977. 